Thorax (1973), 28, 349.

\title{
A long-term review of dermal grafts and bronchial reconstruction ${ }^{1}$
}

\author{
IAN MONK \\ The Thoracic Unit, Royal North Shore Hospital of Sydney, St. Leonards, New South Wales, Australia \\ Between 1953 and 1962, 21 patients presented with bronchial strictures. Bronchial reconstruction \\ was carried out on 15 of these while a dermal graft was employed in another six patients. The \\ follow-up period, therefore, is between 10 and 20 years. Bronchial structures lend themselves to \\ satisfactory reconstruction. This review, however, showed that late contraction of a dermal graft \\ may occur even two years after operation.
}

Between 1953 and 1962, 21 patients presented with bronchial strictures. Nearly all of these were due to healed tuberculosis. In one group of 15 patients it was possible to carry out bronchial reconstruction to overcome the stricture. In another group of six patients a dermal graft was employed.

\section{CLINICAL FEATURES}

The most outstanding feature in these cases was the distress caused to the patient which was out of proportion to the deformity. Some of the patients had been treated as suffering from asthma. In all cases, however, stridor could be heard on expiration, and often on inspiration, if listened for without a stethoscope. Recurrent infection was a not uncommon problem. Recurrent atelectasis was seen in one patient only.

\section{ASSESSMENT}

A bronchoscopy was performed in all patients and the severity and the level of the stricture were identified. In those patients who eventually came to operation it was usually not possible to visualize beyond the stricture so that a bronchogram was necessary to delineate its length. A bronchogram was necessary also to determine whether or not damage in the form of bronchiectasis was present distally.

\section{BRONCHIAL RECONSTRUCTION}

The different reconstructive procedures carried out can be seen in Table I. In four patients it was possible to carry out a resection of the stricture and then perform an end-to-end anastomosis.

1 Based on a paper read to the Thoracic Society.
In one patient, a resection and end-to-end anastomosis was necessary for both main bronchi. In this patient these operations were carried out with an interval of three months between. The bilateral strictures followed active tuberculous bronchitis.

T A B LE I

BRONCHIAL RECONSTRUCTION

\begin{tabular}{lllll|l}
\hline Resection and anastomosis & $\ldots$ & $\ldots$ & $\ldots$ & & 4 \\
Longitudinal ellipse, transverse sew-up & & $\ldots$ & 6 \\
Cuff from upper lobe stump & $\cdots$ & $\ldots$ & $\ldots$ & 5 \\
\hline & & & Total & 15 \\
\hline
\end{tabular}

The distress to the patient was extreme and progressed as the active bronchitis was brought under control with antituberculosis drugs, and as the scar tissue formed and contracted. In addition to stridor in this patient, bronchospasm indistinguishable from asthma could be heard in both lungs. Multiple fluffy opacities were seen to be scattered throughout both lungs but these cleared after the strictures were corrected.

In six patients it was possible to correct the stricture either by taking out a longitudinal ellipse of the narrowed area and then sewing this up transversely or by resecting a wedge of tissue to include the stricture. In five patients a diseased left upper lobe was associated with a stricture at the junction of the main and left lower lobe bronchi, which in some cases extended downwards into the area of the apical lower lobe orifice. In order to correct this a cuff of the bronchial stump was retained after removal of the upper lobe and this was fashioned and shaped so as to swing down and widen out the narrowed area below. The stricture was often made worse by the fact that the diseased upper lobe had retracted and 
swung upwards, thus creating an angle between the left main and the left lower lobe bronchi.

FOLLOW-UP ON PATIENTS WITH BRONCHIAL RECONSTRUCTION It was possible to examine personally 13 patients in this group some 10 to 20 years after operation. All but one have been largely or entirely relieved of their symptoms. Of the 12 patients who remain well between 10 and 20 years after operation, eight deny any symptoms. Four of these eight asymptomatic patients, however, when examined and asked to make forced expiration, exhibit slight stridor, although they appear to be subjectively unaware of this. Of these four patients with slight stridor, two submitted to bronchoscopy and in both cases narrowing by $50 \%$ of the normal diameter of the bronchus was noted. Of the four patients who note slight wheeze and a tendency to bronchitis, two submitted to bronchoscopy. Narrowing by at least $50 \%$ was noted in both patients. From these observations it is likely that any patient who complains of slight wheeze or can be shown to have stridor has a narrowing of at least $50 \%$ of the normal diameter of the bronchial lumen.

One patient who is unrelieved was shown to have severe narrowing still present. This patient had a left upper lobectomy for a destroyed tuberculous lobe carried out in 1958. A flap from the upper lobe bronchus was swung down to relieve the stricture. However, recurrent wheeze, stridor, and recurrent infection remained a problem. A thoracoplasty was not performed following the lobectomy and the increase in angulation between the left main and left lower lobe bronchi probably increased the disability. A pneumonectomy has now been carried out on this patient.

The follow-up information on this group is summarized in Table II.

T A B L E I I

13 BRONCHIAL RECONSTRUCTIONS

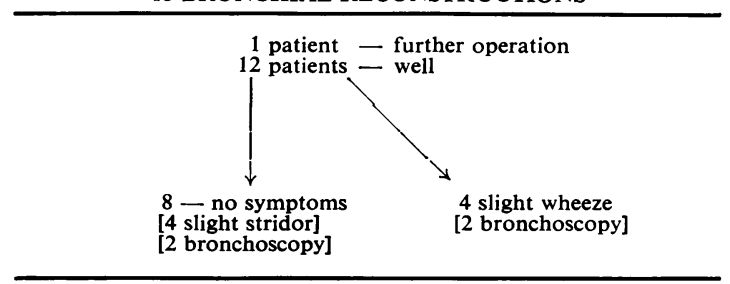

DERMAL GRAFTS

Between 1953 and 1958, six patients presented with long strictures involving the whole of the left main bronchus. All followed active tubercu- $\frac{\overrightarrow{3}}{2}$ lous bronchitis. When all signs of activity were $\frac{C}{5}$ shown to have been controlled and scarring re- $\overline{\frac{\sigma}{5}}$ mained, a dermal graft was used to restore nor- $\widehat{\Phi}$ mal diameter to the lumen of the left main bron- $\frac{0}{0}$ chus. In two patients this was combined with a lobectomy, in one patient a pleurolobectomy, in $\overrightarrow{0}$ one patient a lobectomy and a thoracoplasty were performed, and in one patient a thoracoplasty $\vec{\sigma}^{\circ}$ only was added to the dermal graft procedure. One patient in this group died 10 days after operation from a secondary haemorrhage (see Table III).

\begin{tabular}{|c|c|c|c|c|c|}
\hline Patient & Age & $\begin{array}{c}\text { Opera- } \\
\text { tion }\end{array}$ & Procedures & Result & $\begin{array}{l}\text { Broncho- } \\
\text { scopy }\end{array}$ \\
\hline \multirow[t]{2}{*}{1} & 30 & $\begin{array}{l}\text { May } \\
1953\end{array}$ & $\begin{array}{l}\text { LU } \\
\text { lobectomy, } \\
\text { thoracic }\end{array}$ & $\begin{array}{l}\text { No symptoms } \\
\text { No signs }\end{array}$ & $\begin{array}{l}60 \% \\
\text { normal }\end{array}$ \\
\hline & 25 & $\begin{array}{l}\text { Feb. } \\
1954\end{array}$ & $\begin{array}{l}\text { grait } \\
\text { LU } \\
\text { lobectomy, }\end{array}$ & No symptoms & No \\
\hline 3 & 38 & $\begin{array}{l}\text { Oct. } \\
1955\end{array}$ & $\begin{array}{l}\text { L thoracic } \\
\text { graft }\end{array}$ & $\begin{array}{l}\text { Died } 10 \text { days } \\
\text { after }\end{array}$ & - \\
\hline 4 & 29 & $\begin{array}{l}\text { Jan. } \\
1956\end{array}$ & LU & $\begin{array}{l}\text { No symptoms } \\
\text { No signs }\end{array}$ & Declined \\
\hline 5 & 41 & $\begin{array}{l}\text { May } \\
1957\end{array}$ & $\begin{array}{l}\text { LU } \\
\text { lobectomy, } \\
\text { thoracic } \\
\text { graft }\end{array}$ & $\begin{array}{l}\text { Occasional } \\
\text { wheeze } \\
\text { Stridor } \\
\text { elicited }\end{array}$ & $\begin{array}{l}\text { Normal } \\
\text { at } 18 \mathrm{mth} \\
40 \% \\
\text { Normal }\end{array}$ \\
\hline 6 & 36 & $\begin{array}{l}\text { Sept. } \\
1957\end{array}$ & $\begin{array}{l}\text { LU } \\
\text { lobectomy, } \\
\text { graft }\end{array}$ & $\begin{array}{l}\text { Reported } \\
\text { well }\end{array}$ & - \\
\hline
\end{tabular}

All of these patients presented with extremely distressing wheeze and recurrent non-tuberculous 3 infection. In one patient recurrent atelectasis of the left lung was observed. A bronchoscopy in all patients revealed extreme narrowing up to or $\mathrm{O}$ very close to the carina. A biopsy taken from the area of stricture revealed no evidence of active $\frac{7}{0}$ tuberculosis but evidence of mature fibrous tissue. All of them were under treatment with anti- $N$ tuberculosis drugs which at that time consisted of $N$ streptomycin and PAS. The antituberculosis N therapy was continued throughout the period of ${ }_{\sigma}^{\mathcal{O}}$ operation and for at least six months after operation. Figure 1a shows a stricture of the left main $\stackrel{\circ}{\circ}$ bronchus which has been partly shown with lipiodol. The area of stricture is opened out by an incision along the membranous part of the left main bronchus. A gusset of dermis, laced and $\mathbb{D}$ stiffened with stainless steel wire, is then sutured $\frac{?}{\mathbb{D}}$ into place. Figure $1 \mathrm{~b}$ is a tomogram film of the $\stackrel{2}{2}$ patient taken 18 years after the insertion of such a graft. The left main bronchus is widened and $\delta$ the lacing of stainless steel wire can be seen. 


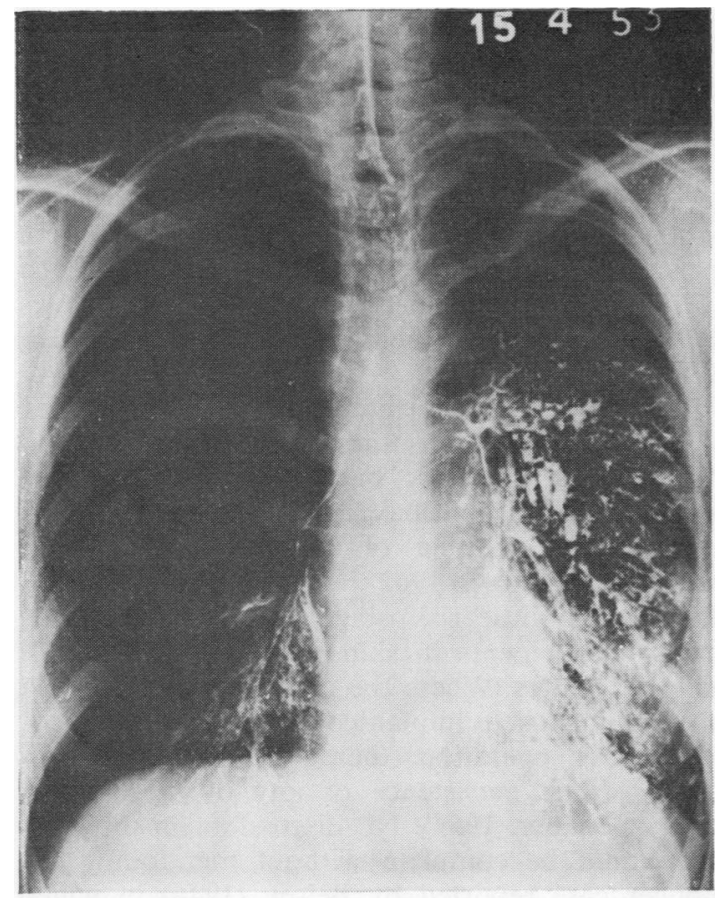

(a)

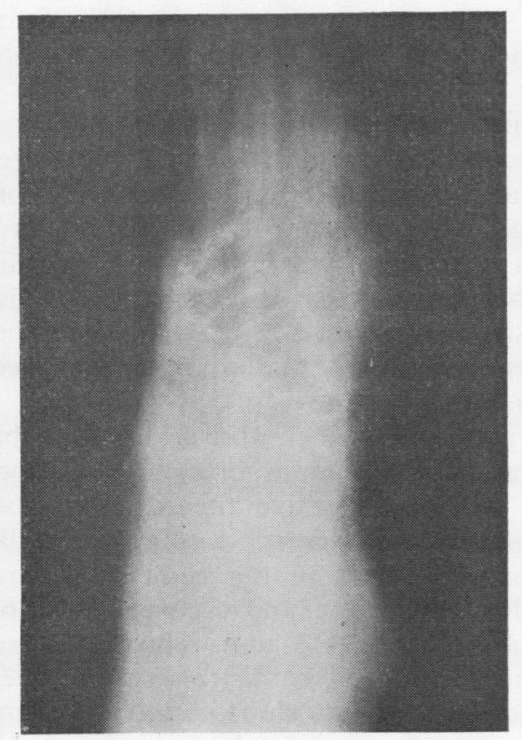

(b)

FIG. 1. Shows the placement of a gusset of dermis in order to widen out the bronchial stricture.
FOLLOW-UP OF PATIENTS WITH DERMAL GRAFTS

The five surviving patients were reviewed in 1970, a period of 12 to 17 years. All are clinically well and in Table III the observations are summarized. Two of these patients have not been personally examined as they have left the State of New South Wales. However, their medical attendant, who in each case is an experienced physician, reports that they are well and that no abnormality can be detected on clinical examination. Three of the patients have been reviewed personally and the findings are as follows.

Patient 1 (Fig. 1) This patient was bronchoscoped in February 1970, that is, 17 years after the original operation. Slight narrowing to about $60 \%$ of normal was found at the junction of the left upper and left lower lobe area. This patient is clinically well and there is no abnormality on physical examination. A bronchoscopy was carried out in this case three weeks after the operation in 1953 and at that time considerable oedema was present so that the instrument could not be passed into the left lung. Some thick mucus and degenerating epithelium were removed with biopsy forceps. Following this the patient reaerated the left lung, which had become collapsed, and made an uneventful convalescence, remaining well up to the present time.

Patient 4 This patient was examined clinically and no abnormality could be detected. The patient declined to have a bronchoscopy.

Patient 5 This patient was bronchoscoped in 1970 , that is, 13 years after the original operation, and narrowing of the left main bronchus was noted. The adolescent-sized Negus bronchoscope could not be passed beyond about $1 \mathrm{~cm}$ from the carina. This patient has been well clinically, and on normal breathing no abnormality can be detected. However, on forced expiration stridor can be heard. This patient regards herself as having normal breathing. In this case a bronchoscopy had been performed about 18 months after the original operation and on that occasion the normal adult-sized instrument could be passed into the left lower lobe. It is of interest and some significance, therefore, that late contraction of the graft has occurred in the 11 years following the bronchoscopy carried out soon after the original operation.

\section{DISCUSSION}

The cause of bronchial stricture is not always tuberculosis, although the majority were in the the above series. Apart from the patients reviewed, 
who were selected because of the length of the follow-up period, a number of additional patients have been treated. On three occasions following an upper lobectomy for non-tuberculous disease a stricture occurred in the area of the stump of the removed upper lobe. In two of these patients the disease process was a non-specific inflammatory pneumonitis. The third patient had a left upper lobectomy performed for a destroyed lobe, the disease eventually being identified as (to use one of its names) 'mucus impaction'. In two of these patients some distortion of the area contributed to the narrowing. Stridor became apparent within six to 12 months of the operation after an apparently uncomplicated convalescence, and a secondary operation was necessary in all three patients within a year. A plastic reconstruction of the area was carried out, consisting of a wedge excision of the narrowed area with resuture. Examination of the removed portion of bronchus revealed no abnormality other than chronic nonspecific inflammatory changes.

From time to time, when carrying out bronchoscopies on patients with chronic bronchitis with or without bronchospasm, one has observed minor degrees of stricture formation usually at the beginning of the right or left lower lobe bronchi. A biopsy revealed non-specific chronic inflammatory changes in such cases. In none of these patients has the stricture appeared to be severe enough to warrant surgical correction.

In all the patients who have come to operation, one has been struck by the great subjective distress the patients experience. In several patients the bronchial orifice was reduced to a few millimetres and the distress appeared to be roughly in proportion to the degree of narrowing. These observations, together with those of other patients in whom minor degrees of stricture formation have been noted, suggest that the lumen of the bronchus can be narrowed to about $50 \%$ of its normal diameter before there is any subjective awareness on the part of the patient of an abnormality. On the other hand, when a partially obstructed bronchus becomes completely occluded, one may observe that symptoms and signs disappear and the patient becomes more comfortable. This is occasionally seen in patients with carcinoma.

Stridor was the most striking physical sign in this group of patients and is best assessed without the stethoscope. The physical sign is always present on expiration but when inspiratory stridor was present the stricture was noted always to be very severe.

The question of bronchospasm is of interest.
Presumably with serious subtotal obstruction the patient has to make forced expiratory effort aE every breath and this induces generalized broncho $\overline{\overline{\bar{T}}}$. spasm.

All the patients who had long strictures requiring dermal grafts were women, while only two of the patients requiring bronchial reconstruction were men. This female sex preponderance has beennoted by other surgeons and presumably relates. to the smaller size of the bronchial tubes in womers (Gebauer, 1950).

The use of implanted dermal grafts has beerio of interest to surgeons for many years (Peer and Paddock, 1937). They have been used for the repair of hernias and have been favourably reported on by a number of surgeons over a long period (Cannaday, 1942 ; Mair, 1945). It seems that there is little risk of growth of some of the contained elements in skin such as sweat glands or hair follicles. Where the opportunity has arisere to examine such implanted material months of years after operation, there has been little eviD dence of the persistence of any of these strucs tures (Gebauer, 1953). No discussion on this sub ject would be complete without mentioning the pioneer case reported by Belsey (1946) in whiclo he described the use of a stainless steel supported fascia lata graft in repairing the trachea.

When placing a dermal graft in the bronchiab position it has been recommended that the tene dency should be to over-correct the narrowe area (Gebauer, 1950). The late shrinkage observe in one of these patients would testify to the correctness of this original conception.

Bronchoscopic examination of the grafted area. shows an appearance indistinguishable from nor 8 mal mucosa. A biopsy will show normal bronchiaß mucosa with cilia. Experimentally and clinically it has been shown that bronchial mucosa is fairly aggressive and that it will grow over the grafe quite quickly in a matter of some weeks or
months.

The patient described above, in whom bilatera strictures of both main bronchi developed fol lowing healing of active tuberculous bronchitiso is of particular interest. A diaphragm-like ob struction developed in the right main bronchus just below the carina and eventually the openin contracted to about $3 \mathrm{~mm}$. This was associatedo with great subjective distress and generalize $\bar{b}$ bronchospasm. Over a short period an attempt was made to carry out bronchial dilatation but this was unsuccessful. Occasionally a dilatation may be helpful in a patient with a tracheal stricture following prolonged tracheostomy but the pro巳 cedure rarely appears to be helpful. Following 
the correction of this patient's bilateral strictures the complete relief of generalized bronchospasm as well as the disappearance of multiple presumably non-specific areas of pneumonitis was most striking.

\section{CONCLUSION}

1. Narrowing of the bronchial tube to less than half the size of its normal diameter will cause distress out of proportion to the deformity. Recurrent infection may occur.

2. Provided a bronchus is not rendered avascular by crushing, damage, or disease, it will heal extremely well.

3. Bronchial mucosa is aggressive and will grow over a dermal graft within a few weeks or months.

4. Reasonably elegant surgical methods are available to relieve patients with bronchial strictures and the results are excellent provided that no permanent damage has been done to the lung distal to the obstruction.

5. Even two years after operation late contraction of a dermal graft may occur.

\section{REFERENCES}

Belsey, R. (1946). Stainless steel wire suture technique in thoracic surgery. Thorax, 1, 39.

Cannaday, J. E. (1942). The use of the cutis graft? in the repair of certain types of incisional herniae and other conditions. Ann. Surg., 115, 775.

Gebauer, P. W. (1950). Plastic reconstruction of tuberculous bronchostenosis with dermal grafts. $J$. thorac. cardiovasc. Surg., 19, 604.

- (1953). Bronchial resection and anastomosis. J. thorac. cardiovasc. Surg., 26, 241.

Mair, G. B. (1945). Preliminary report on the use of whole skin-grafts as a substitute for fascial sutures in the treatment of herniae. Brit. J. Surg., 32, 381.

Peer, L. A., and Paddock, R. (1937). Histologic studies on the fate of deeply implanted dermal grafts. Arch. Surg., 34, 268. 